\title{
ALICE SHALVI: A FORÇA DESCONHECIDA QUE $O$ MUNDO PRECISA CONHECER
}

\section{ALICE SHALVI: THE UNKNOWN POWER THAT THE WORLD MUST KNOW}

\author{
Andréa Kogan ${ }^{1}$
}

A palavra trailblazer em inglês, cujo significado é pioneiro(a), desbravador(a), pode ser bem colocada de início aqui nesta resenha. Talvez seja uma das definições possíveis diante da importância desta mulher, autora do objeto desta resenha, embora colocar dentro de "amarras de definição" tudo o que Alice fez e continua fazendo é uma tarefa cada vez mais difícil. Precisamos destas definições e amarras, mas nem sempre é possível tê-las. Alice Shalvi é muito mais do que conseguirei colocar nesta resenha, ou mais do que ela conseguiu explanar sobre ela mesma neste livro.

Também não é possível listar todas as atividades realizadas por Alice Shalvi nos seus 93 anos completados em outubro de 2019 e descrevê-las devido ao número de cargos que ocupou, funções que exerceu, vidas que mudou e premiações que obteve.

Para escrever sobre Alice, fez-se necessário uma delimitação (dada por mim mesma) do que ler, como ler e por que ler (além de seu próprio livro) — não é possível ler tudo sobre ela. 0 mundo em que entrei, nas redes e nas obras, para conhecer Alice Shalvi, além de Never a Native, é amplo demais, muito, mas muito maior do que esta resenha pode cobrir.

Quando Alice Shalvi lançou seu Never a Native, a Tablet Magazine ${ }^{2}$ publicou uma reportagem escrita por Letty Cotin Pogrebin, (mais precisamente em outubro de 2019) chamada: "A israelense mais famosa sobre a qual você nunca ouviu falar" (no original: The most famous Israeli you've never heard of ${ }^{3}$.

Acredito que este título também caberia ao público brasileiro. Mas Alice Shalvi não merece mais ser desconhecida nos tempos atuais por inúmeros motivos. Alguns ela consegue descrever em seu livro (de forma muito íntima e ao mesmo tempo olhando para o mundo,

\footnotetext{
1 Andréa Kogan é professora e assistente acadêmica do Laboratório de Política, Comportamento e Mídia da Fundação São Paulo/PUC-SP. É Pós-doutoranda em Ciências da Religião pela PUC-Minas, Doutora em Ciência da Religião pela PUC-SP e autora do livro "Espiritismo Judaico". Link para o Currículo Lattes: http:// lattes.cnpq.br/2157640816595416. ORCID ID: https://orcid.org/0000-0003-2930-2590. E-mail para contato: andreakogan@terra.com.br.

2 Cf. em <https://www.tabletmag.com/jewish-life-and-religion/272440/alice-shalvi-never-a-native>. Acessado em 07/02/2020.

3 Todas as citações que estão em língua inglesa foram traduzidas pela autora desta resenha e, sendo assim, responsabilidade desta.
} 
mostrando para os leitores que muitas das coisas que ela fez não estão neste memoir, estão nos feitos que ela deixa para a sociedade). ${ }^{4}$

Listo aqui alguns feitos: títulos de doutor honoris causa pela University of Judaism de Los Angeles, pelo Gratz College da Philadelphia, pelo Jewish Theological Seminary de New York, pela Brown University, pelo Instituto Weizmann de Ciências, dentre outros. Muitos prêmios, poucos livros, mas muitos artigos. E ressalto o Israel Prize - prêmio mais importante de Israel pelas conquistas (Lifetime achievement) e contribuições para a sociedade israelense (ano de 2007).

Antes de entrarmos na vida da autora, vale esclarecer que o judaísmo de Alice Shalvi está além de uma religião somente. Marshall T. Meyer (1930-1993), o rabino americano que trabalhou durante anos em Buenos Aires, parafraseou as palavras do poeta e dramaturgo romano Terêncio (século II a.C.) da seguinte forma: "sou judeu e nada humano me é estranho". Isto é o que precisamos ter em mente. Na página 197 do seu livro, ela nos diz: "nothing human is alien to us". Usando também os mesmos termos descritos acima.

A professora do departamento de religião da Universidade de Princeton, Leora Batnitzky, escreveu um livro fundamental em 2011 chamado "How Judaism Became a Religion" (Como o judaísmo se tornou uma religião - tradução livre, pois o livro só existe em língua inglesa), que ajuda a entender a questão do judaísmo para além de somente uma religião. De acordo com a autora, temos que pensar no judaísmo como religião, nacionalidade e cultura até o chamado Iluminismo Judaico (Haskalá) do século XVIII (aqui permito-me fazer uma síntese somente). De acordo com Batnitzky:

\begin{abstract}
"A partir do século XVIII, pensadores judeus modernos têm se preocupado com a questão se o judaísmo pode ou não se encaixar na categoria protestante de religião. Afinal, o judaísmo é historicamente uma religião de lei, portanto: prática. Aderência à lei religiosa, que, no mínimo parcialmente - ou talvez em sua maioria - de natureza pública, não parece se encaixar na categoria de fé ou crença, que, por definição é individual e privada. É o embate entre a categoria moderna de religião e o judaísmo que levanta muitas das tensões criativas do pensamento judaico moderno e, ao mesmo tempo, se o judaísmo ou a judaicidade (Jewishness) seja religião, cultura ou nacionalidade" (L. Batnitzky, 2011, p. 2).
\end{abstract}

Esse é o judaísmo presente de Alice Shalvi e que talvez precise ser esclarecido em quaisquer textos sobre judaísmo/tradição judaica, pois é necessário irmos além do judaísmo estereotipado e talvez ortodoxo e pensarmos em um judaísmo humanista, como o de Marshall T. Meyer e de Alice Shalvi.

Alice conta com detalhes sobre sua infância: foi criada em uma família judia ortodoxa, mas de forma geral nunca se sentiu absolutamente confortável com as leis rabínicas, principalmente tudo que dizia respeito ao papel da mulher, papéis menores e indiferentes às necessidades e gostos femininos. Nasceu na Alemanha e foi criada com o irmão mais velho.

${ }^{4}$ É importante ressaltar que este livro é um memoir. Uso este termo em inglês, por ser o melhor para descrever o gênero, não sendo uma autobiografia propriamente dita. 
Seus pais sempre se consideraram judeus sionistas e, no começo da década de 1930, a família mudou-se para a Inglaterra. Alice estudou em Cambridge e formou-se em Literatura Inglesa.

A respeito do nome Never a Native, Shalvi explica que morou em muitos lugares, mas nunca se sentiu nativa em nenhum deles. Fez aliás no ano de 1949, um ano após a declaração do estado de Israel e lá vive até hoje. Diz que seus seis filhos podem, sim, dizer que são israelenses nativos. Ela não. Havia conhecido a Palestina em 1947 e não queria mais voltar à vida na Inglaterra. Disse que nunca havia sentido esse "pertencimento" - queria lá construir sua casa. $\mathrm{O}$ que aconteceu, dois anos depois, como descrito. E é em Israel que mora até hoje.

Casou-se com Moshe Shalvi - seu parceiro de vida em todos os momentos, falecido em 2013, e teve seis filhos. Moshe está muito presente em todo o livro de Alice. Em todas as páginas vemos a parceria, a dedicação e o conhecimento desse grande homem que sempre apoiou e incentivou a esposa. Impossível escrever em um texto único sobre quem foi Moshe Shalvi para Alice. Vemos sempre claramente sua admiração e amor.

Seis semanas depois de chegar em Israel, Alice começou a lecionar. Shalvi nunca diria que seria professora - não estava nem em seus sonhos. Mas descobriu que era o que amava fazer (dentre outras coisas). Foi professora de muitos israelenses conhecidos - como o poeta Yehuda Amichai - , ativistas e poetas. Na página 51 de seu livro, ela conta o quanto já sabia, na adolescência, o importante papel de ser professor ao lembrar de uma professora sua: "eu lembrava do papel proeminente que cada professor deve ter, não importa qual disciplina ensine, como um educador, uma pessoa que pode (e deve ter) um impacto moral duradouro na vida de seus alunos". (Shalvi, 2018, p. 239).

Alice foi determinante na educação de jovens mulheres ao liderar a escola Pelech para meninas, em 1975. A ideia de Shalvi foi sempre uma educação igualitária entre homens e mulheres, formando indivíduos "informados, comprometidos e engajados com um estado judaico democrático e moderno que conceda privilégios iguais a todos os cidadãos, independentemente de raça, religião ou gênero" (Shalvi, 2018, p. 239).

A trajetória de Alice na escola Pelech é narrada por ela no livro, mas destaco aqui uma passagem, quando foi incorporado no currículo da instituição um programa de 4 anos de "história total" 2014 - Total History, que combinava uma cobertura tradicional de eventos sociais e políticos, com um estudo de literatura, filosofia, arte e música. Como ela mesma disse: que melhor lugar para se estudar as Cruzadas do que Jerusalém?

Pelech não é hoje somente o nome de uma escola, é um conceito educacional/ pedagógico, de acordo com Shalvi. Alice chama suas ex-alunas e alunas sempre de "my girls".

A Pelech é descrita atualmente como uma escola experimental de Ensino Médio para meninas que levam uma vida religiosa tradicional dentro de uma atmosfera de tolerância e engajamento em uma sociedade abrangente. Há cerca de 250 meninas na escola, as quais cursam um programa rigoroso de estudos no mesmo nível (grifo meu) das escolas religiosas de meninos - estudam humanidades, ciências sociais e etc.

\footnotetext{
5 Fazer aliá é a expressão que se usa quando as pessoas imigram para Israel.
} 
Alice foi reitora da escola rabínica Schechter. Convidada em 1990, quando achava que já estaria aposentada, vivendo uma vida mais tranquila, recebeu uma ligação do Rabino Daniel Goldfarb do Schechter Institute e aceitou o convite.

Destaca-se o programa de mestrado inédito em women's studies - um campo na qual a instituição foi pioneira. A instituição cresceu e atualmente é uma grande organização educacional israelense que se dedica à ampla disseminação dos estudos judaicos para TODOS os israelenses (vale ressaltar que a palavra em caixa-alta está presente no texto do site consultado). 0 objetivo dessa é oferecer uma educação judaica pluralista a diversas populações, promovendo uma sociedade democrática segura em suas raízes judaicas. 0 Instituto acredita que oferecer estudos judaicos em um ambiente que seja tanto academicamente crítico e comprometido com a tradição, fornece uma dimensão vital, até então ausente, à educação israelense. Também oferece o maior programa de mestrado em estudos judaicos de Israel, com mais de 500 alunos, de diferentes ortodoxias e ambientes, e até hoje já formou 92 rabinos, líderes espirituais da linha Masorti (um judaísmo conservador, porém progressista, baseado em pluralismo, igualdade e democracia, em termos gerais). E algo essencial derivado de Alice Shalvi - conferências e pesquisas sobre os valores centrais do Instituto, entre elas: promover o papel das mulheres na vida judaica, criando abordagens modernas em relação a assuntos como a lei judaica, além de promover o uso das artes nos estudos judaicos.

Alice é realmente a mãe do feminismo israelense, luta em todos os sentidos para os direitos das mulheres na política, no exército israelense, no mercado de trabalho, na mídia e em todo lugar. Não é simplesmente a "mãe", mas uma ativista incansável.

Em uma tradução livre, no capítulo The Vulcano Erupts, o vulcão entra em erupção, Alice faz um resumo do que é a sua vida:

\footnotetext{
"A vida é um rio. Uma metáfora antiga, um clichê, mas apropriado. Nós temos nossos afluentes, as gerações que vieram antes de nós. As águas fluem por muitas milhas, algumas vezes de forma tranquila, outras transformadas em corredeiras perigosas. Depois elas podem mudar, transformando-se em várias correntes que, finalmente, chegam ao mar do desconhecido. No meu caso, depois da infância, adolescência, dias de estudante, primeiros trabalhos profissionais, casamento e maternidade, um vulcão entrou em erupção. Ele transformou meu cenário pessoal, desaguando em uma série de afluentes turbulentos não planejados: feminismo, educação, rebelião religiosa, ativismo político e reforma social. Tudo isto formou um grande delta antes de gradualmente apaziguar-se em um mar de esquecimento sem sol, mas inexplorado" (Shalvi, 2018, p. 191).
}

Alice tem noção de seu papel como uma das principais representantes do movimento feminista de Israel, mas creio que sua personalidade tímida relata no seu livro só parte dos seus feitos em relação ao assunto. Quem representa uma figura de tamanha importância não fala tudo isso sobre si mesma. A modéstia impera ou a personalidade não tem dimensão da realidade. 
Há muitas narrativas de extrema importância nessa obra, nas quais Alice conta alguns fatos ligados a sua luta pelas mulheres na sociedade israelense - passagens felizes e que geraram frutos importantes e passagens tristes, infrutíferas, mas com lutas. Dentre as várias fotos do livro, há uma impactante: Alice queimando ketubot. Uma ketubá (singular, plural: ketubot) é um contrato de casamento judaico, com as obrigações do marido e da mulher (teoricamente). Porém, o que é visto nas ketubot é algo mais unilateral, o que as mulheres devem fazer nos casamentos, as obrigações femininas. Alice queimando tais documentos é uma imagem muito impactante.

Alice é fundadora do Israel Women's Network, uma organização apartidária que luta pelos direitos das mulheres e homens na sociedade israelense. Dentre muitos relatos que se relacionam com estas lutas, destaco aqui uma discussão muito comum que sempre aconteceu nos meios judaicos (principalmente pós-Segunda Guerra Mundial).

Em 1975 uma lei foi aprovada em Israel legalizando o aborto com base na idade — se a mulher tivesse menos de 17 ou mais de 40, se a gravidez fosse resultado de um relacionamento proibido (como estupro ou incesto) ou se a saúde física ou mental do bebê ou da mãe estivesse em risco. Em todos os casos a permissão só seria dada por um conselho constituído de 5 pessoas: médicos e assistentes sociais com a opinião adicional de um rabino. Alice conta que o conflito neste debate presencial era inevitável. 0 rabino começou a sua fala com o previsível: “Crescei e Multiplicai! É um PECADO não ter filhos”. Uma das companheiras de grupo de Alice disse: "Mulheres têm o direito de decidir por si mesmas, o direito de controlar seus próprios corpos. Você não pode forçar uma mulher a ter um filho que ela não quer". A ira do rabino foi enorme e assim, veio a fala esperada: "Nós perdemos 6 milhões no Holocausto, você quer matar mais judeus". E a resposta: "E você quer matar mais mulheres. Mulheres não são só úteros. Elas são seres humanos, como você!” (Shalvi, 2018). Discussão mais do que necessária no mundo contemporâneo e talvez ainda um "tabu” nos meios judaicos até hoje.

Destaco aqui algumas discussões em forma de tópicos, e que podem ser analisadas no livro com mais profundidade:

- Em 1979 Alice tem a oportunidade de subir até Torah e emocionada, com lágrimas nos olhos, ela percebe que, se fosse homem, teria tido esta experiência 40 anos antes;

- No movimento criado por ela, uma das principais lutas era aumentar o número de mulheres no Knesset (parlamento israelense);

- Luta por mulheres em uma sociedade (israelense) obcecada pela fertilidade, centrada na família e na cultura conservadora, e a mulher sozinha, solteira e sem filhos não recebia quase nenhuma atenção (Shalvi, 2018, p. 260);

- A criação de uma conferência internacional para escritoras mulheres;

- Investigação e denúncia de tráfico de mulheres da antiga União Soviética que vinham para Israel e tornavam-se prostitutas, sem perspectiva e direitos pela frente. 
Alice consegue algo extremamente difícil: o respeito por todas as ortodoxias religiosas dentro do judaísmo. Não uma aceitação total, é claro, mas respeito em relação a tudo que fez, tudo que é, e tudo que tornou possível na sociedade israelense.

No final do livro, ela nos conta que o "Espírito Divino que a inspira não tem gênero. É ilimitado no tempo e no espaço. Vasto e abrangente." (Shalvi, 2018, p. 318). Com uma vida inteira cheia de lutas para conseguir igualdade de gênero, ela nos mostra como isso é possível. É necessário dizer que precisamos de mais Alices Shalvis em todos os idiomas, em todos os lugares - um mundo com mais Alices.

Termino esta resenha desejando que a leitura deste livro seja feita por muitos. Desejando também que o judaísmo humanista, engajado e combativo de Alice Shalvi se torne mais visível. Agir como judeu, tal como Alice, Marshall Meyer e tantos outros, não é somente uma questão religiosa, mas uma questão essencialmente humana. Aqui, as palavras de um dos maiores filósofos e rabinos do século XX, Abraham Joshua Heschel (1907-1972), que possibilitou, de certa forma, os percursos que percorremos hoje. Heschel, ao caminhar com Dr. Martin Luther King, na passeata em Selma, lutando pelos direitos civis, enfatizou: "minhas pernas estavam rezando". (Heschel, Susannah 2012)

Ao lermos esse livro, percebemos o quanto Alice também reza e pratica o seu judaísmo, das formas mais contundentes, impactantes e necessárias possíveis.

\section{REFERÊNCIAS BIBLIOGRÁGICAS}

BATNITZKY, Leora. How Judaism Became a Religion: An introduction to Modern Jewish Thought. New Jersey: Princeton University Press, 2011.

FAINSTEIN, Daniel. Judaísmo, Direitos Humanos e Espiritualidade: uma biografia intelectual do Rabino Marshall T. Meyer. São Paulo: Comunidade Shalom, 2013.

HESCHEL, Abraham J. O último dos profetas: uma introdução ao pensamento de Abraham Joshua Heschel. São Paulo: Manole, 2002.

HESCHEL, Susannah. Their feet were praying. 10 jan. 2012. Disponível em: < https://jewishweek.timesofisrael.com/their-feet-were-praying/> Acesso em 30 de outubro de 2020.

SHALVI, Alice. Never a native. Londres: Halban Publishers, 2018. 322 p. ISBN: 978-1-905559-98-5.

Alice Shalvi: a mãe do feminismo israelense. Stand with us Brasil. Disponível em: <https:// www.facebook.com/watch/?v=2051492278252960 >. Acesso em 01 de outubro de 2019.

TABLET MAGAZINE. The most famous Israeli you've never heard of. Outubro de 2018. Disponível em: <https://www.tabletmag.com/jewish-life-and-religion/272440/alice-shalvinever-a-native> Acesso em 01 de outubro de 2019. 
The Jerusalem Foundation - 50 $0^{\text {th }}$ anniversary: Pelech Religious Experimental High School for Girls. Disponível em: <https://jerusalemfoundation.org/old-project/pelech-religious-experimental-high-school-for-girls/> Acesso em 05 de outubro de 2019.

The Schechter Institutes. Disponível em: <https://schechter.edu/>. Acesso em 30 de setembro de 2019.

The Schechter Institutes: Professor Alice Shalvi: Women's Wisdom has built a home in Jerusalem. 2018. Disponível em: <https://www.youtube.com/watch?v=B5_DusBhXlI>. Acesso em 10 de setembro de 2019. 